apparent paraloxes. At the same tirse it camnot fail to be instructive. May 7

\section{Cumulative Temperature}

ATTENTION has been called in your valuable paper to the idea of registering cumulative temperatures by means of a pendulum, by M. von Sterneck, vol, xvii. p. 308, and this has called forth several letters. One gentleman has put forward my nawe as having devised means with some success. In an instrument exhibited at the Royal Society soirée, 1876 , I could have left the matter resting at this point, but $I$ am induced to write by the letter of your correspondent, " $\mathrm{B}$," in vol. xvii. p. 486 , who says, "The chief merit in this matter will belong to the person who puts the idea into a working form which can be proved capable of giving accurate results." As I think that I have fairly attained this end, or at least pointed out the way to it, with your permission I will describe the means which appears by the correspondence interesting to many of your readers. In my cumulative temperature clock the important element, the pendulum, is constructed as follows:-A steel cylindrical tube 32 inches long, $1 \frac{3}{4}$ inch internal diameter; is hermetically closed at both ends. A rod is attached to one of the ends, which is placed uppermost, to comnect this pendulum with the clockwork in the ordinary manner. An airtight division is made across the tube or chamber at 5 inches from the upper end. A small tube leads from this division to the bottom of the chamber. A conical plug is in scrted in the upper chamber, to be hereafter described. A screw plug is placed under the small tube in the outer tube to enable the upper chamber to be filled with mercury. When the pendulum is so constructed, the lower screw plug is removed, and the upper chamber and leading tube filled with mercury by means of a small funnel. In this full state the mercury is boiled, and the whole inverted. It then becomes a steel barometer. To convert it into a thermometer, a small air-hole is made in the outer tube (this is not shown in the engraving), and this hole is closed up with a small air-tight cock filled with a porous material. When this is screwed on and turned off, it is isolated from atmospheric pressure, and the mercury rises into the upper chanber by any increase of temperature causing expansion of air in the tube, and sinks in the same manner by loss of temperature, so that the pendulum becomes simply an air thermometer. The pressure of the air by expansion within the tube in the rising of the mercury changes the centre of oscillation of the pendulum and accelerates the clock, and vice verst.

The clock is specially constructed to count beats only in units, tens, \&c., up to ten millions, and the number of beats per day, week, month, or year, becomes the unit of temperature for the period. The exact length of time of each pendular oscillation being governed by the temperature at the time, the method becomes equal to one accurate observation at every second of time.

The difficulties of construction and refinement required upon this general description are of two kinds, mathematical and mechanical. The models that I exhibited at the Royal Society's soirée were imperfect, being of blown glass. The difference of oscillation per day for $\mathrm{I}^{\circ}$ Fahrenheit, was in these about 50 , as taken at the Lambetin Observatory by the late Col. Strange. In the steel instruments described there would be about roo oscillations additional per day for the rise of each degree centigrade. The mechanical difficulties are simply constructive. To obtain perfectly vacuum proof chambers, and to follow correctly the outline of the plug to be immersed in the vacuum. chamber. Also the adjustment of the correct volume of mercury, and the density of the contained air, by means of the cock, and the application of heat or cold to the outer case. The mathematical requirements are corrections. Thus: if the chambers were simply cylindrical, the mercury that rose by the pressure would have a different oscillation value for every point of space through which it rose. This might be corrected to equal scale value by making one or both the mercury-chambers conical, but it is much more simply done by inserting a conical plug in the upper chamber. There would also be a correction for the expansion of the mercury and the steel case, and from any irrationality in the expansion of the contained air. The whole of this correction being derived from heat might be made by one correction in the immersed plug. Prof." Stokes, Sec, R.S., kindly offered to calculate the exact form of this ping for me from data I was to supply. But $I$ was ill shortly after this, and unable to attend to the matter, so I let it drop, but have the clocks and pendulums ready to complete some time hence.

I send a diagram engraving which shows the principle of the pendulum No. 2, for cumulative temperatures. No. I is for

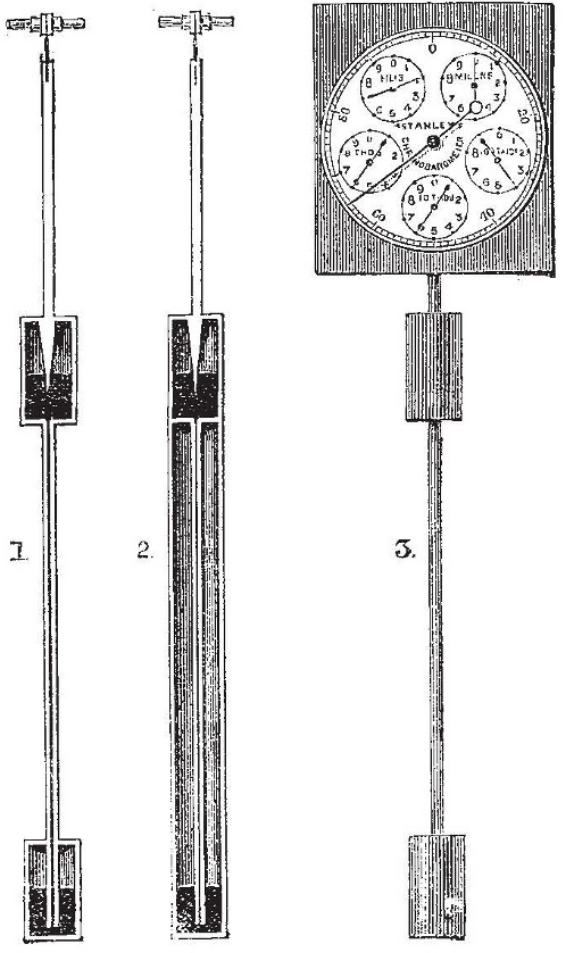

taking cumulative pressures upon the same system, if the science of meteorology should require such exact means of obtaining permanent records of pressure and temperature for long periods as for months or years. WM. F. STANLEY

South Norwood, April 22

\section{THE INTERIOR OF THE EARTH ${ }^{1}$}

SIR GEORGE AIRY remarked that the nature $S$ of the subject was different from any upon which he ever lectured before, in regard to its indefiniteness and to the difficulty he should have if he considered it to be his duty to lead them definitely up to some point. He could only give them some idea the theory to which he wished to lead them, and in doing so he would advert collaterally to a good many points which might be valuable. He proposed to divide his address into three parts. The first would relate to the measures of the earth; the second to observations on temperature ; and the third to the manner in which they might suppose the earth to have been formed, especially with regard to the nebular hypothesis; and after that he would add some remarks on the conclusions to which these lead.

He described the process called triangulation, by which a large part of the contour of the globe is covered, and by which it is possible to lay down a map on which the distance between any one point and any other point is ascertained to within a few inches; how that this was valuable in ascertaining the dimensions and figure of the earth with the aid of the zenith sector, an instrument for measuring the apparent distances of stars from the point overhead. He showed on a large globe the principal lines of measurement which had up to this time

I Abstract of Address at the Cumberland Association fur the Advance ment of Liternture and Science, by Sir George B Airy, K.C.B., F.R.S. Astroitomer-Royal. Revised by the author. 